\title{
Effect of hot rolling history and cooling rate on the phase transformation of plain carbon steel
}

\author{
I. Schindler ${ }^{1 *}$, S. Rusz ${ }^{1}$, P. Opěla ${ }^{1}$, J. Rusz $^{1}$, Z. Solowski ${ }^{2}$, K. M. Čmiel ${ }^{2}$ \\ ${ }^{1} V \breve{S} B$ - Technical University of Ostrava, Faculty of Metallurgy and Materials Engineering, \\ 17. listopadu 15, 70833 Ostrava, Czech Republic \\ ${ }^{2}$ Třinecké železárny a.s., Prưmyslová 1000, 73961 Třinec, Czech Republic
}

Received 6 January 2017, received in revised form 3 February 2017, accepted 6 February 2017

\begin{abstract}
Bars from plain carbon steel were hot rolled in the new laboratory semi-continuous mill with the application of various total deformation. The phase transformation temperatures were determined from the surface temperature-time curves registered in the course of free cooling of the rolled products. The $A_{\mathrm{r} 3}$ temperature was influenced by the total amount of the previous deformation, and it increased with the descending rolling temperature. The obtained results were verified by metallographic analyses, and they were compared with the CCT and DCCT diagrams, constructed from the results of dilatometric tests. The performed experiments illustrate the useful cooperation of plastometric and laboratory hot rolling experiments, as well as the potentiality of a simple study of the non-isothermal decomposition of austenite using analysis of the cooling curves.
\end{abstract}

Key words: plain carbon steel, transformation temperature influenced by deformation, (D)CCT transformation diagrams, laboratory hot rolling, microstructure, grain size

\section{Introduction}

Conditions of cooling of the hot-formed steels play a key role in the control of structural and mechanical properties of the rolled products and forgings. The temperature of the last reduction and subsequent cooling rate affect the kinetics of the structure processes fundamentally, especially of static recrystallization, and of various phase transformations [1-3]. The Continuous Cooling Transformation (CCT) diagrams of particular steel, less frequently constructed also with consideration of the influence of the previous deformation (DCCT diagrams), are in this case a very valuable help - Mein [4], Siefert [5]. These diagrams are rarely designed as artificial neural network models - Trzaska [6], Ghosh [7]. As for the physical methods, results of dilatometric tests performed at different, but always constant, cooling rates are used for the study of the phase transformation temperatures $[8,9]$. However, in industrial operating conditions, the cooling rate of material gradually changes - with the decreasing temperature it decreases, which can be further complicated by the evolution of the exothermic phase transformations $[10,11]$, leading even to a local increase in temperature. Therefore, it proved very useful to combine the knowledge of the DCCT diagrams with the data provided by real cooling curves. These curves can be registered for example at the laboratory mill, by measuring the surface temperature of the freely cooled rolled product by the thermal scanner. The cooling rate can be in this case controlled by the size of the rolled product (more precisely by its cross-section). Figure 1 shows an example of such results. Using the mathematical analysis of the cooling curves (e.g. smoothing and numerical differentiation of noisy temperature-time data in the Origin software), it is possible to calculate the continuously changing cooling rates and the temperatures of the phase transformations corresponding to them - see e.g. Fig. 2.

The aim was to obtain information on the influence of the temperature and the size of the accumulated strain, as well as cooling rate, on the kinetics

*Corresponding author: e-mail address: ivo.schindler@vsb.cz 


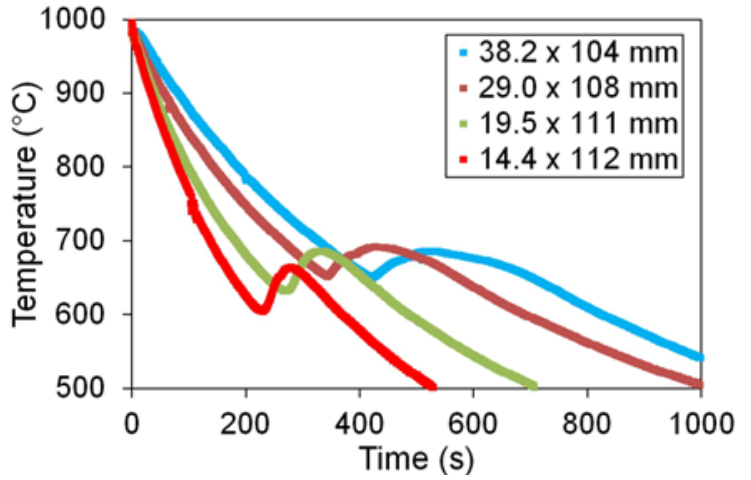

Fig. 1. Cooling curves influenced by the cross-section of laboratory hot rolled sample (spring steel $51 \mathrm{CrV} 4$ ) [12].

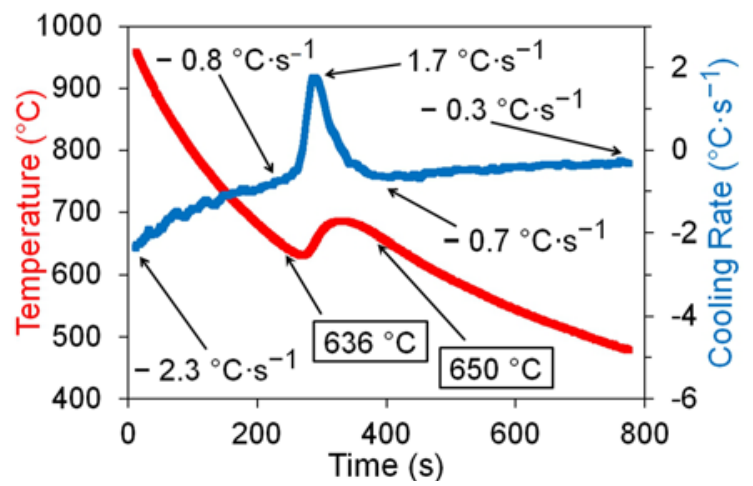

Fig. 2. Analyses of the cooling curve (see Fig. 1 - section $\left.19.5 \times 111 \mathrm{~mm}^{2}\right)[12]$.

of the austenite $\rightarrow$ ferrite transformation of the plain carbon steel (with $0.085 \mathrm{C}, 0.68 \mathrm{Mn}, 0.22 \mathrm{Si}, 0.004 \mathrm{Al}$ in wt.\%) and on the resultant microstructure. Dilatometric tests and cooling of laboratory rolled products were used for this purpose.

\section{Materials and methods}

\subsection{Used experimental equipment}

Hot Deformation Simulator HDS-20 at the VŠB-TU Ostrava is a modular set of devices with main components of the servo-hydraulic plastometer Gleeble 3800 and simulation module Hydrawedge II [13]. Using the closed control loop and various sophisticated modes of deformation by uniaxial and/or plain-strain compression, as well as by tension, it meets the most demanding requirements to dynamic thermal-mechanical testing and simulation of real multi-reduction forming or heat treatment of metallic materials. The LVDT (Linear Variable Differential Transformer) based dilatometer compatible with the
HDS-20 system is designed for accurate measurements of material transformations [14]. The quartz contact tips are rated for continuous operation from 11 to $1300{ }^{\circ} \mathrm{C}$ and for time-limited operation up to $1400^{\circ} \mathrm{C}$. This transducer can be used even for measuring transformations after deformation with the strain rates up to $10 \mathrm{~s}^{-1}$ with no adverse effects.

The considerable commercial success of dilatometric tests after the previous deformation led in 2015 to the acquisition and commissioning of the second dilatometric system, cooperating with the simulator HDS-20 [15]. Scanning non-contact optical dilatometer and extensometer uses a high-intensity GaN long life LED combined with a high-speed laser displacement CCD sensor provides measurements with no moving parts. This unit has twice the speed of conventional laser-based measuring units. The controller display has an easy to view LCD screen, which includes a real-time CMOS camera image of the specimen target to enable an easy aligning of the transmitter and receiver units, as well as knowledge of the exact position of the measurement beam with respect to the specimen and thermocouple location. The green LED technology ensures both quick and accurate measurement (with a resolution of $0.2 \mu \mathrm{m}$ ) reliably and durably, the built-in CMOS monitor camera enhances the usability. The optical dilatometer measures transformation also after the previous deformation, even at the maximum temperature of $1200^{\circ} \mathrm{C}$.

Computer-controlled semi-continuous laboratory mill for rolling is primarily intended for optimization simulations of conditions of the round bars rolling controlled by temperature and cooling rate, as well as for investigation of the processes of intensive hot forming. At present, it allows reversible rolling on smooth rolls with a diameter of $350 \mathrm{~mm}$, as well as reversing or continuous rolling on rolls with the gauge flat oval/circle - see Fig. 3a. The main gas furnace with the maximum temperature of $1300{ }^{\circ} \mathrm{C}$ and several mobile or stationary electric furnaces are used for heating the material before rolling, or for interstage heating, or (also in combination with quenching tank equipped with a circulating pump) for heat treatment or controlled decelerated cooling of cut-offs of the laboratory rolled products.

The reversing rougher was in 2015 equipped with an induction system for a preheating of input bars or interstage reheating of the rolled stock - see Fig. 3b. It enables primarily rolling of round bars with a minimum diameter of $15.8 \mathrm{~mm}$ from the round bars with a maximum diameter of $55 \mathrm{~mm}$ or the squares up to $84 \mathrm{~mm}$. Another set of rolls with the gauge rhomb/square was designed for rolling of the smallest square bars $14 \mathrm{~mm}$ from the squares of max. $45 \mathrm{~mm}$ or from the round bars with a diameter of max. $50 \mathrm{~mm}$.

The surface temperature measurement is ensured by four high-speed LANDSCAN Infrared Linescanners 

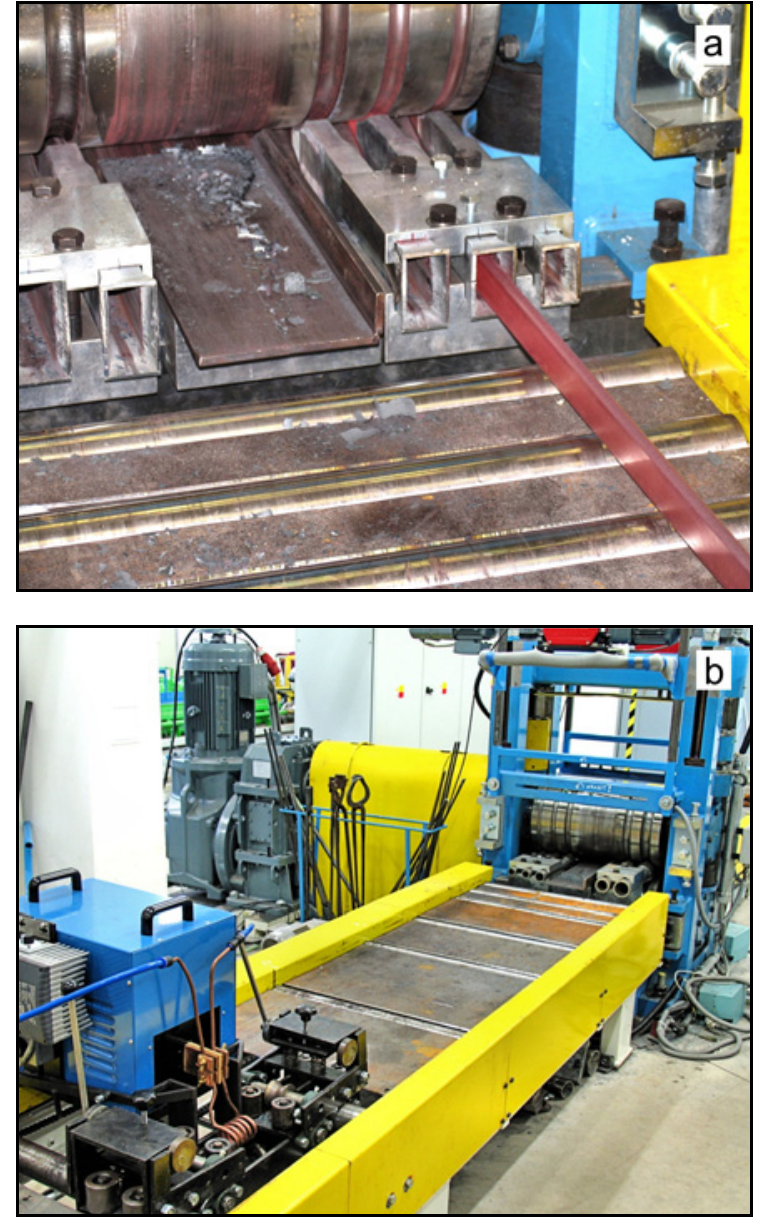

Fig. 3. Reversing rougher of the laboratory mill: (a) semifinished product with a flat-oval section is inserted into the round pass, (b) general view with a transversely movable system of induction heating in the foreground.

that can be fixed in several brackets according to the operative requirements (with ranges of $600-1400{ }^{\circ} \mathrm{C}$, $400-1200^{\circ} \mathrm{C}$, or $300-1000{ }^{\circ} \mathrm{C}$ ). The continuous finishing train (Fig. 4a), with the horizontal/vertical arrangement of four rolling stands, can process input round blanks with the diameters ranging from 20.0 to $6.4 \mathrm{~mm}$. It is applied for rolling of final round bars with a diameter of $12.3-5.5 \mathrm{~mm}$ at the highest rolling rate of $2 \mathrm{~m} \mathrm{~s}^{-1}$. It uses mainly the rolled products from the laboratory rougher, dimensions of which are adjusted to the requirements of the finishing train. The rolled product can be immediately quenched or freely cooled on air, or cooled in an accelerated manner by pressure water (with controllable intensity) see Fig. 4b, or cooled in decelerated manner in the processor-controlled annealing furnaces $[16,17]$.

\subsection{Transformation diagrams}

Dilatometric cylindrical samples with a diameter of
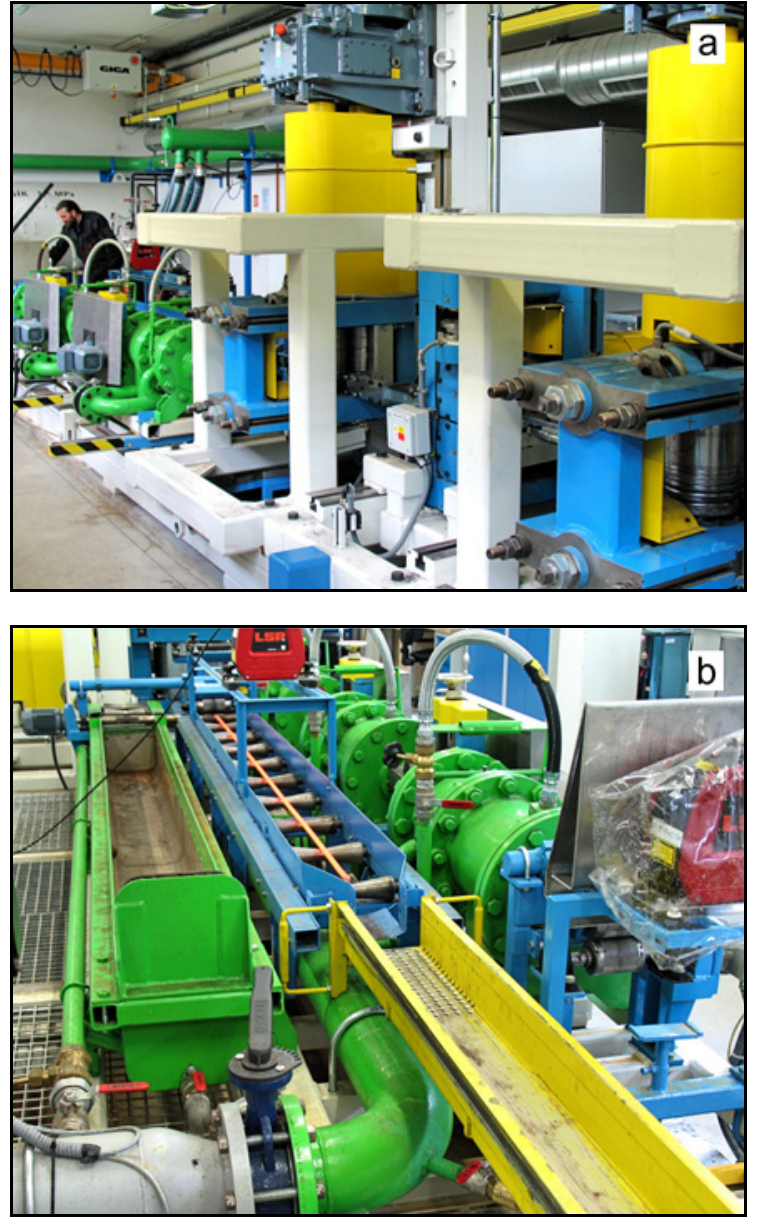

Fig. 4. Continuous finishing train of the laboratory rolling mill: (a) at the foreground three of four rolling mill stands, in the background an outlet section with the system of accelerated cooling of the rolled product, (b) cooling systems: from the left a quenching tank, roller conveyor with freely cooled rolled product and three rings of the system of controllable accelerated cooling by pressure water.

$6 \mathrm{~mm}$ were uniformly austenitized at the temperature of $900^{\circ} \mathrm{C}$ for 120 seconds, and they were then cooled by the selected constant cooling rates $\left(0.2-25^{\circ} \mathrm{C} \mathrm{s}^{-1}\right)$ down to a room temperature [5]. Some of the samples were also subjected immediately after austenitization at the temperature of $900^{\circ} \mathrm{C}$ to a compressive deformation of the magnitude of $e=0.35$, namely for the constant strain rate of $1 \mathrm{~s}^{-1}$. After the analysis of the thus obtained dilatometric curves, it was possible to construct for the given steel the CCT and DCCT diagrams, the graphical comparison of which is presented in Fig. 5.

Due to a limited range of the cooling rates and to the low carbon content in the given steel, only the temperatures Ferrite-Start $\left(A_{\mathrm{r} 3}\right)$ and Pearlite-Start $\left(A_{\mathrm{r} 1}\right)$ were determined on the dilatation curves. It is evident from Fig. 5 that the previous deformation resulted in the expansion of the ferritic field, but its influence on 
Ta ble 1. Temperature conditions at reversing rolling of individual bars

\begin{tabular}{|c|c|c|c|c|c|c|c|c|}
\hline \multirow{2}{*}{$\frac{\text { Temperature }\left({ }^{\circ} \mathrm{C}\right)}{\left.T_{0} \text { (before } 1^{\text {st }} \text { pass }\right)}$} & \multicolumn{8}{|c|}{ Individual Rolled Samples } \\
\hline & 1200 & 1200 & 1150 & 1100 & 1050 & 1000 & 950 & 900 \\
\hline$T_{1}$ (before $2^{\text {nd }}$ pass) & 1007 & 1088 & 1051 & 999 & 955 & 930 & 877 & 825 \\
\hline$T_{2}$ (after $2^{\text {nd }}$ pass $)$ & 964 & 1056 & 1007 & 960 & 921 & 898 & 867 & 830 \\
\hline$T_{\mathrm{m}}$ & 986 & 1072 & 1029 & 980 & 938 & 914 & 872 & 828 \\
\hline$\Delta T$ & -43 & -32 & -44 & -39 & -34 & -32 & -10 & 5 \\
\hline
\end{tabular}

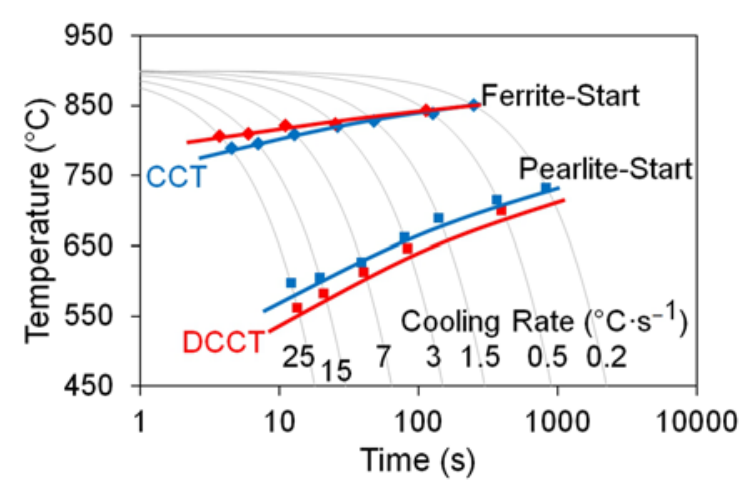

Fig. 5. (D)CCT diagram of the tested steel.

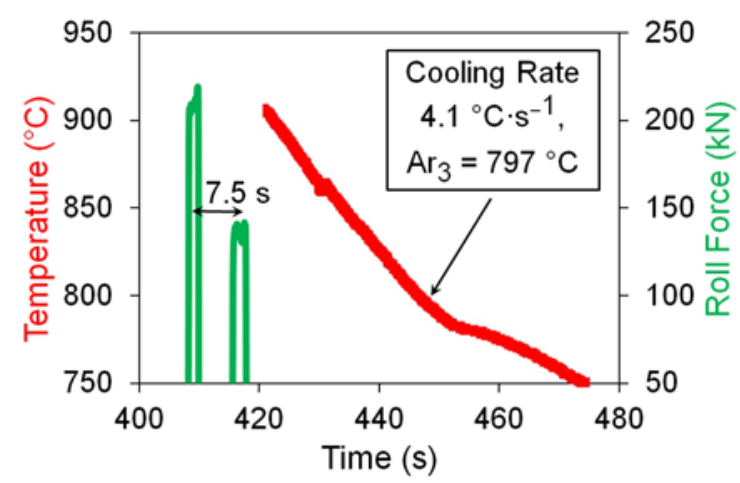

Fig. 6. Time dependence of the surface temperature and the total roll force during reversing rolling from the temperature of $1050^{\circ} \mathrm{C}$.

the transformation temperatures was only moderate. In dependence on the cooling rate the measured values of $A_{\mathrm{r} 3}$ ranged from 788 to $850{ }^{\circ} \mathrm{C}$ (CCT) and from 806 to $843^{\circ} \mathrm{C}(\mathrm{DCCT})$, while the values of $A_{\mathrm{r} 1}$ ranged from 596 to $731^{\circ} \mathrm{C}(\mathrm{CCT})$ and 561 to $699^{\circ} \mathrm{C}$ (DCCT).

\subsection{Reversing rolling and cooling of bars $\varnothing 15.8 \mathrm{~mm}$}

Rolling experiments were carried out in two stages. First, the bars were rolled by two reductions on the reversing rougher. The initial rods with a diameter of $20.0 \mathrm{~mm}$ were uniformly preheated in an electric resistance furnace to $1200^{\circ} \mathrm{C}$, and they were then individu- ally cooled freely on air to the selected rolling temperature $\left(900-1200{ }^{\circ} \mathrm{C}\right)$. The rods were afterward inserted into another electric resistance furnace and heated to the specific rolling temperature. After a short equalizing dwell each sample was rolled to the diameter of $15.8 \mathrm{~mm}$, i.e. with a total elongation (or with reduction of its cross-section) of 1.6. The rolls with a maximum working diameter of $350 \mathrm{~mm}$ rotated at the rate of $20 \mathrm{~min}^{-1}$. Time diagram of the rolling is evident from Fig. 6. Altogether three thermal scanners were used for measurement of the temperature at different stages of the experiment. The rolled products cooled freely on air, whereas their surface temperature was registered.

Table 1 summarizes the temperature data on rolling of individual bars. The surface temperature of the samples was recorded immediately before and after the second reduction pass; it is, therefore, possible to calculate the mean temperature of the material in the second pass $T_{\mathrm{m}}=\left(T_{1}+T_{2}\right) / 2$, or the difference of temperatures $\Delta T=T_{2}-T_{1}$. It is evident that at the lowest rolling temperatures the evolution of deformation heat compensates the processes of heat removal from the formed material into the surroundings (the work rolls, atmosphere).

The transformation temperatures $A_{\mathrm{r} 3}$ and $A_{\mathrm{r} 1}$ were determined for each rolled product by analysis of the cooling curve and an average diameter of ferrite grains was determined metallographically on the cross section.

\subsection{Continuous rolling and cooling of the bars $\varnothing 9.8 \mathrm{~mm}$}

The bars $\varnothing 15.8 \mathrm{~mm}$ were uniformly heated to the temperature of $1000{ }^{\circ} \mathrm{C}$, and after free cooling and equalization dwell at the rolling temperature (800$1000^{\circ} \mathrm{C}$ ), they were rolled by four reductions on the continuous train of the laboratory rolling mill. A total elongation of 2.6 corresponded to achieving of the final dimension of $\varnothing 9.8 \mathrm{~mm}$. One rod heated directly to the temperature of $1200{ }^{\circ} \mathrm{C}$ was rolled for comparison only. Circumferential speeds of the rolls ranged from $1.0 \mathrm{~m} \mathrm{~s}^{-1}$ ( $1^{\text {st }}$ stand) to $2.0 \mathrm{~m} \mathrm{~s}^{-1}$ ( $4^{\text {th }}$ stand). The surface temperature was registered by thermal scanners immediately after finish rolling, and the curve corresponding to the free cooling of the bars on the roller 
Ta ble 2. Temperature conditions at continuous rolling of individual bars

\begin{tabular}{lrrrrrr}
\hline Temperature $\left({ }^{\circ} \mathrm{C}\right)$ & \multicolumn{5}{c}{ Individual Rolled Samples } \\
\hline$T_{0}$ (before $1^{\text {st }}$ pass) & 1200 & 1000 & 950 & 900 & 850 & 800 \\
$T_{4}$ (after $4^{\text {th }}$ pass) & 1112 & 972 & 936 & 905 & 870 & 876 \\
$T_{\mathrm{m}}$ & 1156 & 986 & 943 & 903 & 860 & 838 \\
$\Delta T$ & -88 & -28 & -14 & 5 & 20 & 76 \\
\hline
\end{tabular}

Ta b l e 3. Information obtained after reversing rolling of the bars $\varnothing 15.8 \mathrm{~mm}$

\begin{tabular}{rccccc}
\hline$T_{\mathrm{m}}\left({ }^{\circ} \mathrm{C}\right)$ & Cooling rate $\left({ }^{\circ} \mathrm{C} \mathrm{s}^{-1}\right)$ & $A_{\mathrm{r} 3}\left({ }^{\circ} \mathrm{C}\right)$ & Cooling rate $\left({ }^{\circ} \mathrm{C} \mathrm{s}^{-1}\right)$ & $A_{\mathrm{r} 1}\left({ }^{\circ} \mathrm{C}\right)$ & $D(\mu \mathrm{m})$ \\
\hline 1072 & 4.7 & 796 & 1.7 & 648 & 16.9 \\
1029 & 4.6 & 796 & 1.7 & 653 & 15.8 \\
986 & 4.5 & 796 & 1.7 & 651 & 15.2 \\
980 & 4.2 & 797 & 1.7 & 655 & 14.8 \\
938 & 4.1 & 797 & 1.7 & 651 & 12.7 \\
914 & 4.1 & 798 & 1.7 & 651 & 11.0 \\
872 & 4.1 & 804 & 1.7 & 649 & 9.5 \\
828 & 4.1 & 812 & & & 9.5 \\
\hline
\end{tabular}

Ta b le 4. Information obtained after continuous rolling of the bars $\varnothing 9.8 \mathrm{~mm}$

\begin{tabular}{rccccc}
\hline$T_{\mathrm{m}}\left({ }^{\circ} \mathrm{C}\right)$ & Cooling rate $\left({ }^{\circ} \mathrm{C} \mathrm{s}^{-1}\right)$ & $A_{\mathrm{r} 3}\left({ }^{\circ} \mathrm{C}\right)$ & Cooling rate $\left({ }^{\circ} \mathrm{C} \mathrm{s}^{-1}\right)$ & $A_{\mathrm{r} 1}\left({ }^{\circ} \mathrm{C}\right)$ & $D(\mu \mathrm{m})$ \\
\hline 1156 & 8.6 & 786 & 2.8 & 644 & 14.0 \\
986 & 7.9 & 795 & 3.0 & 645 & 12.3 \\
943 & 7.7 & 796 & 2.9 & 646 & 10.3 \\
903 & 7.6 & 798 & 2.8 & 646 & 9.9 \\
860 & 7.1 & 807 & 2.0 & 643 & 7.9 \\
838 & 7.5 & 809 & 2.9 & 7.9 \\
\hline
\end{tabular}

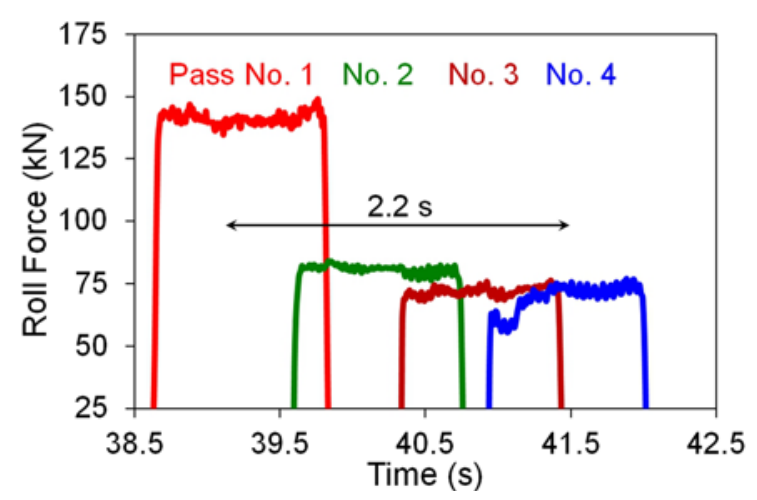

Fig. 7. Time dependence of total roll forces at continuous rolling from the temperature of $800^{\circ} \mathrm{C}$.

conveyor was constructed. Figure 7 illustrates the continuity and speed of the rolling process.

The values $T_{\mathrm{m}}$ and $\Delta T$ presented in Table 2 are related to the temperature before the first pass and right after the fourth pass. It is apparent from Fig. 8 that the temperature increase caused by deformation heat is very intense at low-temperature continuous rolling.

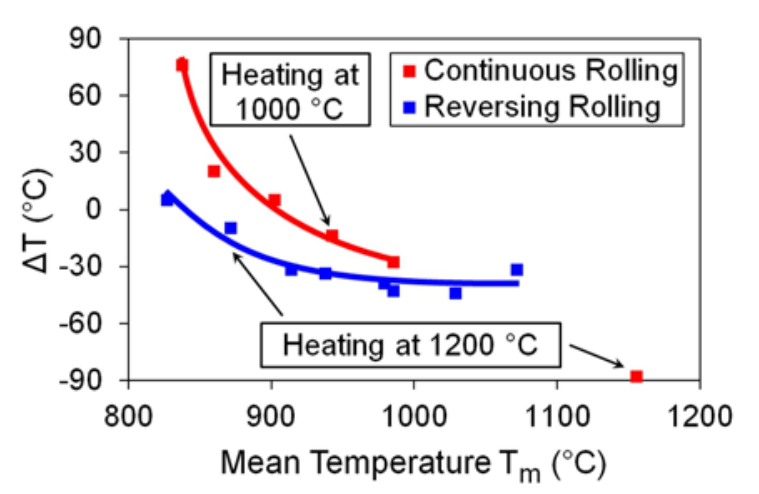

Fig. 8. Influence of deformation heat at various modes and rolling temperatures.

\section{Results and discussion}

Micrographs in Fig. 9 document the influence of the rolling method and temperature on the final ferritic-pearlitic structure, differing mainly by the grain size.

Tables 3 and 4 summarize the results obtained 

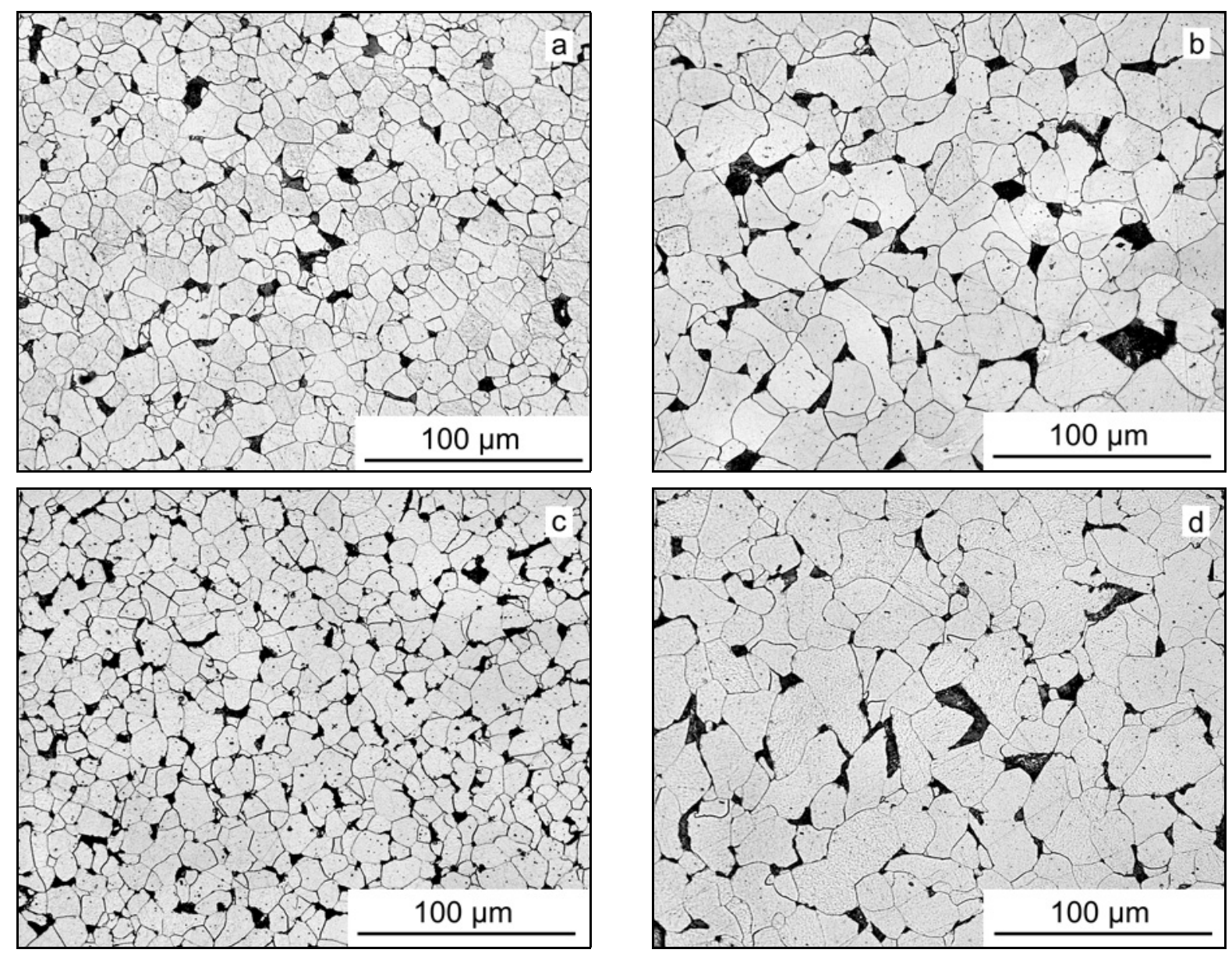

Fig. 9. Microstructure of selected laboratory rolled products: (a) reversing rolling $-T_{\mathrm{m}}=828^{\circ} \mathrm{C}$, (b) reversing rolling $T_{\mathrm{m}}=1072^{\circ} \mathrm{C},(\mathrm{c})$ continuous rolling $-T_{\mathrm{m}}=838^{\circ} \mathrm{C}$, and (d) continuous rolling $-T_{\mathrm{m}}=1156^{\circ} \mathrm{C}$.

by the cooling curves analysis and by metallographic analysis of individual laboratory rolled products. For transformation temperatures $A_{\mathrm{r} 3}$ and $A_{\mathrm{r} 1}$ the corresponding real cooling rates are also shown. The quantity $D(\mu \mathrm{m})$ is a mean grain diameter of the resulting structure, determined by the linear method under the standard EN ISO 643 using the software QuickPHOTO MICRO.

The temperatures $A_{\mathrm{r} 1}$ were slightly affected by the cooling rate, but they were practically not sensitive to the rolling temperature. As it is apparent from Fig. 10, in the case of the temperature $A_{\mathrm{r} 3}$ the situation was different - in particular at the temperatures $T_{\mathrm{m}}<900^{\circ} \mathrm{C}$ a significant increase of the temperature of the beginning of the transformation austenite $\rightarrow$ ferrite took place with the decreasing rolling temperature. The point, corresponding to the continuous rolling from the temperature of $1200^{\circ} \mathrm{C}$, is of course beside the overall trend (similarly as in Fig. 8), which can be explained in this case particularly by different size of the initial austenite grains. It is noteworthy that it is possible within the scatter of experimental data to fit the points, corresponding to the reversing and continuous rolling with different levels of deforma-

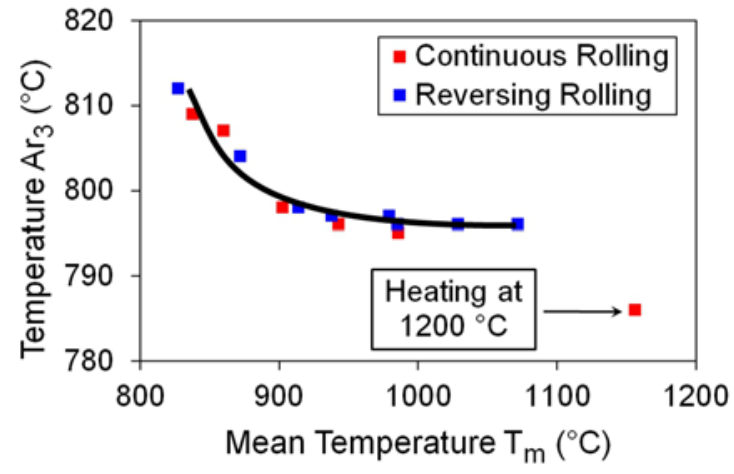

Fig. 10. Influence of the rolling temperature on the transformation temperature $A_{\mathrm{r} 3}$.

tion and different cooling rates, with a single common curve.

It follows from Fig. 11 that the final grain size was significantly influenced by all changed parameters of the experiment. Bigger accumulated strain and higher cooling rate resulted in achievement of a finer grain in the case of continuous rolling than it was in the case 


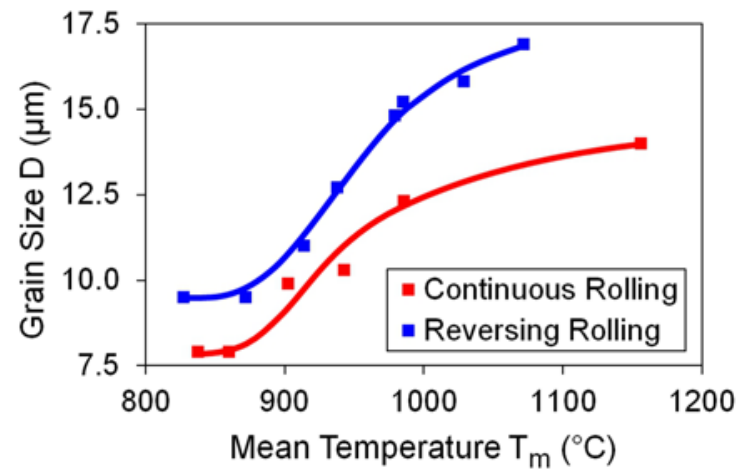

Fig. 11. Influence of the mode and temperature of rolling on the transformation temperature and final grain size.

of the reversing rolling at a similar finish rolling temperature. With the decreasing temperature $T_{\mathrm{m}}$, the grain size gets reduced in both modes of rolling, but the given trend is quite complicated - an intensive decrease of the given curve is observed particularly in the temperature range of approx. $870-1000^{\circ} \mathrm{C}$, at the lowest temperatures this decrease is already stopped and a decrease of the finish rolling temperature loses its sense from the viewpoint of grain refinement. The exact explanation of the obtained dependences is obviously hindered by a number of varying experimental parameters and by influences of various structureforming processes (austenite recrystallization - mostly static, at high-temperature continuous rolling possibly even dynamic; coarsening of the recrystallized austenite grains and kinetics of the transformation austenite $\rightarrow$ ferrite during cooling after deformation).

Comparison of the temperatures $A_{\mathrm{r} 3}$, determined by dilatometer for analogical deformation temperatures and cooling rates (see the (D)CCT diagram in Fig. 5), or from the cooling curves registered at the rolled bars by the thermal scanners, is quite interesting. The $A_{\mathrm{r} 3}$ temperatures after rolling were approx. by $20-30^{\circ} \mathrm{C}$ lower in comparison with the values determined by dilatometer. Apart from the different history of heating and forming of the samples, which affect the size of the austenite grain entering into the phase transformation austenite $\rightarrow$ ferrite, it is necessary to take into account also the differences of temperature fields in the dilatometric sample (with high uniformity of temperature in its volume), and in the rolled bar (when the measured surface temperature is more or less lower than the temperature in the axial part).

\section{Conclusions}

The bars with a diameter of 15.8 or $9.8 \mathrm{~mm}$ were obtained by reversing or continuous rolling of the plain carbon steel with $0.08 \% \mathrm{C}$ on the laboratory mill, and they were subsequently cooled on air. The combined influence of the finish rolling temperature, of the total deformation and the cooling rate on the temperatures of phase transformations, and on the size of the resulting grain was investigated. The $A_{\mathrm{r} 1}$ temperatures were slightly affected by the cooling rate, but they practically did not react to the rolling temperature. On the contrary, particularly at the temperatures below $900^{\circ} \mathrm{C}$, a significant increase in the temperature $A_{\mathrm{r} 3}$ occurred with the decreasing rolling temperature, regardless of the forming history. The finest grains were achieved after an intense continuous rolling at a mean temperature of approx. $850^{\circ} \mathrm{C}$.

For comparison, transformation diagrams (D)CCT of the given steel after austenitization at the temperature of $900^{\circ} \mathrm{C}$ were prepared with the use of dilatometer. The previous deformation of the magnitude of 0.35 influenced the transformation temperatures only slightly. The $A_{\mathrm{r} 3}$ temperatures after rolling are by 20 to $30^{\circ} \mathrm{C}$ lower in comparison with the values determined by dilatometer. The CCT diagram of a similar plain-carbon fine-grained construction steel S355J2 was designed [18], also using the Gleeble dilatometry tests. Due to the higher carbon content $(0.14 \% \mathrm{C})$ and lower austenitization temperature (likely $870^{\circ} \mathrm{C}$ ), the $A_{\mathrm{r} 3}$ values are slightly shifted towards lower temperatures in comparison with Fig. 5, and the regions of bainite and martensite occur.

Apart from the different history of the material processing, it is necessary to highlight the difference of temperature fields in a resistance heated dilatometric sample and the rolled bar. The measured surface temperature is always lower than the temperature in the axial part of the rolled bar. From this perspective, too, the research of phase transformations after laboratory rolling corresponds more to the industrial operating conditions and it can provide valuable additional information to transformation diagrams.

\section{Acknowledgements}

This paper was created within the projects LO1203 "Regional Materials Science and Technology Centre - Feasibility Program" and SP2017/62 funded by the Ministry of Education, Youth and Sports of the Czech Republic.

\section{References}

[1] Timoshenkov, A., Warczok, P., Albu, M., Klarner, J., Kozeschnik, E., Gruber, G., Sommitsch, Ch.: Steel Research Int., 85, 2014, p. 954. doi:10.1002/srin.201300198

[2] Verlinden, B., Driver, J., Samajdar, I., Doherty, R. D.: Thermo-Mechanical Processing of Metallic Materials. Oxford, Elsevier 2007.

[3] Kawulok, R., Schindler, I., Kawulok, P., Rusz, S., Opěla, P., Kliber, J., Solowski, Z., Cmiel, K. M., 
Podolínský, P., Mališ, M., Vašek, Z., Vančura, F.: Metalurgija, 55, 2016, p. 357.

[4] Mein, A., Fourlaris, G., Crowther, D., Evans, P.: Mater. Sci. Technol., 28, 2012, p. 627. doi:10.1179/1743284711Y.0000000092

[5] Siefert, J. A., Leister, B. M., DuPont, J. N.: Mater. Sci. Technol., 31, 2015, p. 651. doi:10.1179/1743284714Y.0000000626

[6] Trzaska, J., Dobrzanski, L. A.: J. Mater. Process. Technol., 192, 2007, p. 504.

[7] Ghosh, S. K., Chattopadhyay, P. P., Haldar, A., Ganguly, S., Datta, S.: ISIJ Int., 48, 2008, p. 649. doi:10.2355/isijinternational.48.649

[8] Kawulok, R., Schindler, I., Kawulok, P., Rusz, S., Opěla, P., Solowski, Z., Cmiel, K. M.: Metalurgija, 54, 2015, p. 473.

[9] Rusz, S., Schindler, I., Kawulok, P., Kawulok, R., Opěla, P., Kliber, J., Solowski, Z.: Metalurgija, 55, 2016 , p. 655.

[10] Nürnberger, F., Grydin, O., Schaper, M., Milenin, A.: Steel Research Int., 81, 2010, p. 224. doi:10.1002/srin.200900132
[11] Opiela, M., Zalecki, W., Grajcar, A.: Journal of Achievements in Materials and Manufacturing Engineering, 51, 2012, p. 78.

[12] Schindler, I., Kawulok, R., Kawulok, P., Mališ, M., Vašek, Z., Petrek, T., Rusz, S., Opěla, P.: Kovárenství, 54, 2015, p. 46.

[13] Schindler, I., Kawulok, P.: Hutnické listy, 66, 2013, p. 85.

[14] Gleeble ${ }^{\circledR}$ Systems Catalog (DSI-14-V1). New York, Dynamic Systems Inc. 2014.

[15] Kawulok, R., Schindler, I., Kawulok, P., Rusz, S., Opěla, P., Podolínský, P., Čmiel, K. M., Solowski, Z.: Kovárenství, 2015, 54, p. 23.

[16] Schindler, I., Rusz, S., Kawulok, R., Kawulok, P., Kraus, M., Šula, M., Čmiel, K. M.: Hutnické listy, 66, 2013, p. 13.

[17] Schindler, I., Jurča, R., Rusz, S., Turoň, R., Kawulok, P., Kawulok, R.: Hutnické listy, 68, 2015, p. 59.

[18] Caron, J., Heinze, Ch., Schewenk, C., Rethmeier, M., Babu, S. S., Lippold, J.: Weld. J., 89, 2010, p. 151. 